\title{
Comparative Molecular Resolution STM Imaging of Thiourea, Ethylthiourea, and Sulfur Self-Assembled Adlayer Structures on Silver (111)
}

\author{
Verónica Brunetti, Bárbara Blum, Roberto C. Salvarezza, and \\ Alejandro J. Arvia* \\ Instituto de Investigaciones Fisicoquímicas Teóricas y Aplicadas (INIFTA), \\ Universidad Nacional de La Plata - CONICET, Sucursal 4, Casilla de Correo 16, \\ (1900) La Plata, Argentina
}

Received January 2, 2003. In Final Form: April 9, 2003

\begin{abstract}
Self-assembled adlayer structures of thiourea (TU), ethylthiourea (ETU), and sulfur (S) adsorbed on $\mathrm{Ag}(111)$, from neutral and alkaline aqueous solutions, are investigated with a scanning tunneling microscope operating under potential control. Voltammograms obtained under various different potential routines are very similar for the three substances. At potentials close to $-1.2 \mathrm{~V}$ (versus saturated calomel electrode), a $(\sqrt{ } 7 \times \sqrt{ } 7) \mathrm{R} 19.1^{\circ}$ adlayer structure with superlattice and nearest neighbor distances of $d_{\mathrm{s}}=0.76 \mathrm{~nm}$ and $d_{\mathrm{n}}=0.44 \mathrm{~nm}$, respectively, is imaged, irrespective of the adsorbate molecule. In this potential region, the first pair of conjugated current peaks related to electroadsorption/desorption processes is recorded. As either the electroadsorption time is increased or the applied potential is shifted positively, self-assembled $\mathrm{TU}$ and $\mathrm{S}$ monolayers evolve into more compact structures. TU adlayers compress into hexagonal arrangements with $d_{\mathrm{n}}=0.33 \mathrm{~nm}$, and $\mathrm{S}$ forms adsorbed S-trimers with the initial ordered array superstructure and coverage and shorter $d_{\mathrm{n}}$. On the other hand, ETU only presents the hexagonal arrangement with $d_{\mathrm{n}}=0.44 \mathrm{~nm}$ common to all three adsorbates at the early ordered adsorption stages. The dynamics of adsorbate patterns can be explained by the interplay of adsorbate-substrate and adsorbateadsorbate interactions, principally hydrogen bonding for TU, steric size effects due to ethyl substituents for ETU, and a clustering process assisted by polymerization for S. As TU on $\mathrm{Ag}(111)$ and TU on $\mathrm{Au}(111)$ exhibit similar adlayer structures, the electroadsorption free energy difference was estimated from the electrodesorption voltammetric peaks. The resulting value is similar to the desorption energy differences calculated for other sulfur-containing molecules.
\end{abstract}

\section{Introduction}

The understanding of the structure of outer atomic layers at solid crystal surfaces has attracted considerable attention since the atomic arrangements of these layers determine the electronic properties and reactivity of solid surfaces. Therefore, the ability to control the surface structure at the atomic level is a crucial point for a wide variety of potential applications in, for instance, molecular recognition, sensors, and metal surface protection.

There is current interest in synthesizing and characterizing well-defined metal surfaces covered with a selfassembled monolayer (SAM). A considerable amount of work on this subject has focused on sulfur and sulfurcontaining molecules because their SAMs are rather simple, relatively stable, and easy to prepare. The basic knowledge derived from the behavior of these model systems plays a key role in diagnosing the state of and engineering SAMs.

Thiourea (TU) and its derivatives, at relatively low concentrations, are useful as brightening and leveling agents in metal electrodeposition, ${ }^{1}$ corrosion inhibitors in metal protection, ${ }^{2}$ silver toning agents in photographic papers, ${ }^{3}$ silver tarnish removers, ${ }^{4}$ animal glue liquifiers, ${ }^{3}$ and vulcanization accelerators. ${ }^{3}$ Sulfur adlayers are a well-

* To whom correspondence should be addressed. Tel: (54) 221425-7291. Fax: (54) 221-425-4642. E-mail: ajarvia@inifta.unlp. edu.ar.

(1) Okinaka, Y.; Kato, M. In Modern Electroplating, The Electrochemical Series, 4th ed.; Schlesinger, M., Paunovic, M., Eds.; John Wiley \& Sons: New York, 2000; pp 719-720.

(2) Ulman, A. An Introduction to Ultrathin Organic Films from Langmuir-Blodgett to Self-Assembly, Academic Press: San Diego, CA, 1991 . known poison in heterogeneous catalysis and electrocatalysis, ${ }^{5}$ whereas other adlayers of short-chain sulfurcontaining molecules, such as alkanethiolates, are basic nanostructures for the development of supramolecular systems. ${ }^{5}$

TU is a fairly large polarizable molecule, most likely poorly solvated in aqueous solution, and exhibits acidbase properties ${ }^{6}$ with a protonation constant of 1.44 at 298 K. ${ }^{7,8}$ In alkaline solution, unprotonated TU prevails over a monoprotonated $\left[\mathrm{NH}_{2} \mathrm{CSNH}_{3}\right]^{+}$species that exists

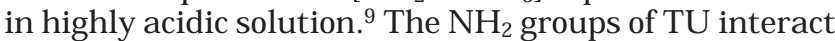
by hydrogen bonding with $\mathrm{H}_{2} \mathrm{O}$ and $\mathrm{H}^{+}$. ${ }^{10}$ The hydrolysis of TU in aqueous solution is favored by the tautomeric form $\left(\mathrm{H}_{2} \mathrm{~N}\right)(\mathrm{HN}) \mathrm{CSH}^{11-13}$ that in alkaline solution could yield thioureate species as occurs with thiols. ${ }^{14}$ In this context, a complete description of the atomic structure of

(3) Ninth Report on Carcinogens; National Institute of Environmental Health Sciences, U.S. Department of Health and Human Services: Washington, DC, 2001; CAS No. 62-56-6.

(4) Wharton, G. WAAC Newsletter 1989, 11, 4

(5) Rodriguez, J. A.; Dvorak, J.; Jirsak, T.; Liu, G.; Hrbek, J.; Aray, Y.; González, C. J. Am. Chem. Soc. 2003, 125, 276.

(6) Hoffmann, M.; Edwards, J. D. Inorg. Chem. 1977, 16, 3333.

(7) Vasiliev, V. P.; Shorokova, V. I.; Grechina, N. K.; Katrovtseva, L. V. Russ. J. Inorg. Chem. 1978, 23, 1274.

(8) Barliev, J. H.; Conway, B. E. J. Chem. Soc., Faraday Trans. 1996, 92, 3709 .

(9) Davies, G. Inorg. Chem. 1972, 11, 2489. 41 . 1.

(11) Turner, D. R.; Johnson, G. R. J. Electrochem. Soc. 1962, 109 , 382

(12) Reid, E. E. Organic Chemistry of Bivalent Sulfur, Vol. 5; Chemical Publishing: New York, 1963.

(13) Fleischmann, M.; Hill, I. R.; Sundholm, G. J. Elecroanal. Chem. 1983, 157, 359. 
the electrolyte/sulfur-covered metal interface in an aqueous environment deserves special attention.

TU adsorption from aqueous solutions on metals, particularly silver, has been investigated with a variety of experimental techniques and modeled using computational methods. ${ }^{15-20}$ TU adsorption on metals is, however, a rather complex process due to the relatively high reactivity of TU in both the electrolyte solution and the adsorbed state. At present, it seems to be well established that in neutral and alkaline solutions both the canonical and the normal form of the TU molecule coexist; ${ }^{13}$ the canonical form is the species adsorbed on silver, ${ }^{13,20}$ perpendicularly to the surface, ${ }^{13,17}$ and with a cleaved $\mathrm{S}-\mathrm{H}$ bond. ${ }^{20} \mathrm{TU}$ and substituted-TU electroadsorption on metals from dilute acidic aqueous solutions is even more complicated due to the formation of different TU-metal complexes, ${ }^{21-23}$ anion-induced TU-adsorbate reorientation, ${ }^{15,17}$ and molecular chemisorption through other atoms besides the S-head ${ }^{21,24}$ at the surface, and the presence of monoprotonated TU in solution. ${ }^{9}$ Therefore, only Scontaining molecule adsorption from alkaline and neutral solutions will be considered throughout the remainder of this work.

The voltammetric response of $\mathrm{Ag}(111)$ in aqueous $\mathrm{TU}^{17,25}$ is comparable to electrosorption processes of sulfur, ${ }^{26,27}$ alkanethiols, ${ }^{14,28,29}$ and their structural isomers ${ }^{28}$ on $\mathrm{Ag}(111)$, with three main voltammetric pairs of peaks at about $-1.2,-1.0$, and $-0.9 \mathrm{~V}$ (versus saturated calomel electrode (SCE)). The conjugate pair of peaks at about $-1.2 \mathrm{~V}$ (SCE) has been recently associated with the electrosorption of ordered $d_{\mathrm{n}}=0.33 \mathrm{~nm}$ compact hexagonal TU arrays on $\operatorname{Ag}(111) .{ }^{20}$ This same wave, for sulfur and thiols, has been alternatively related to a low-coverage one-electron-transfer oxidative adsorption process of disulfide $\left(\mathrm{HS}^{-}\right),{ }^{26}$ ethanethiolate, ${ }^{14}$ and other short-chain alkanethiolates. ${ }^{28}$ Likewise, a site-dependent adsorption of ordered alkanethiolate arrays ${ }^{29}$ and a dilute/disordered sulfur-atom array ${ }^{27,30}$ have also been proposed. The wave at $-1.0 \mathrm{~V}$, that is shifted to more negative potentials with increasing alkanethiol chain length, ${ }^{28,31}$ has been assigned

(14) Hatchett, D. W.; Stevenson, K. J.; Lacy, W. B.; Harris, J. M.; White, H. S. J. Am. Chem. Soc. 1997, 119, 6596.

(15) Tian, Z. Q.; Lian, Y.Z.; Fleischmann, M. Electrochim. Acta 1990 35,879

(16) Tian, Z. Q.; Li, W. H.; Mao, B. W.; Gao, J. S. J. Electroanal. Chem. 1994, 379, 271.

(17) Szklarczyk, M.; Nhu, N.; Zelenay, P. J. Electroanal. Chem. 1996, 405,111 .

(18) Sobkowski, J.; Smoliñski, S. 52nd Meeting of the International Society of Electrochemistry, San Francisco, September 2-7, 2001; Abstract No. 1027

(19) Brunetti, V.; Blum, B.; Salvarezza, R. C.; Arvia, A. J. Acta Microscopica 2001, 10 (Suppl. I), 147.

(20) Brunetti, V.: Blum, B.: Salvarezza, R. C.: Arvia, A. J.; Schilardi, P. L.; Cuesta, A.; Gayone, J. E.; Zampieri, G. J. Phys. Chem. B 2002, 106, 9831

(21) Bunge, E.; Port, S. N.; Roelfs, B.; Meyer, H.; Baumgärtel, H.;

Chiffrin, D. J.; Nichols, R. J. Langmuir 1997, 13, 85.

(22) Alodan, M.; Smyrl, W. Electrochim. Acta 1998, 44, 299.

(23) Zhang, H.; Ritchie, I. M.; La Brooy, S. R. J. Electrochem. Soc.

D 2001, 148, 146.

(24) Bunge, E.; Nichols, R. J.; Roelfs, B.; Meyer, H.; Baumgärtel, H. Langmuir 1996, 12, 3060.

(25) Yan, M.; Liu, K.; Jiang, Z. J. Electroanal. Chem. 1996, 408, 225 (26) Hatchett, D. W.; Gao, X.; Catron, S. W.; White, H. S. J. Phys. Chem. 1996, 100, 331.

(27) Aloisi, G. D.; Cavallini, M.; Innocenti, M.; Foresti, M. L.; Pezzatini, G.; Guidelli, R. J. Phys. Chem. B 1997, 101, 4774.

(28) Hatchett, D. W.: Uibel, R. H.: Stevenson, K. J.; Harris, J. M.; White, H. S. J. Am. Chem. Soc. 1998, 120, 1062.

(29) Mohtat, M.; Byloos, M.; Soucy, M.; Morin, S.; Morin, M. J. Electroanal. Chem. 2000, 484, 120.

(30) Hepel, M.; Bruckenstein, S.; Tang, G. C. J. Electroanal. Chem. 1989, 261, 389

(31) Widrig, C. A.; Chung, C.; Porter, M. D. J. Electroanal. Chem. 1991, 310, 335 to site-dependent sulfide ${ }^{30}$ and self-assembled thiolate monolayers. ${ }^{14,28}$ On the other hand, for sulfur and thiourea, the voltammetric wave at about $-0.9 \mathrm{~V}$ has been assigned to self-assembled sulfide monolayers, ${ }^{26,27}$ site-dependent sulfide, ${ }^{30}$ and sulfide- ${ }^{30}$ or TU- ${ }^{19}$ multilayers. Therefore, while the voltammetric responses of sulfur and short organosulfur molecules are practically indistinguishable from one another and all species chemisorb through the $\mathrm{S}$ head in neutral and alkaline solutions, a clear picture of adsorption arrangements associated with these voltammetric current peaks is still far from established. The effects of substituent groups, by hindering or modifying certain reactions, could give a better picture of the influence of molecular substituents on the self-assembled adsorbate structures.

The present work focuses on the early stages of electroadsorption and subsequent surface arrangements of three sulfur-containing compounds on $\operatorname{Ag}(111)$ : TU, ethylthiourea (ETU), and sulfur. For all three species, molecular resolution images of ordered structures associated with species electrosorbed at the main voltammetric current peak at about $-1.2 \mathrm{~V}$ (SCE) are obtained with a scanning tunneling microscope (STM) operating under potential control. In situ STM images show a common surface pattern at intermediate coverage and quite different surface arrangements at high coverage, reflecting the role of the different intermolecular forces that dominate each adsorbate-adsorbate interaction.

\section{Experimental Section}

2.1. Sample Preparation. Experiments were performed with a $2 \mathrm{~mm}$ thick and $10 \mathrm{~mm}$ in diameter $\mathrm{Ag}(111)$ single-crystal button, miscut $<2{ }^{\circ} .{ }^{11}$ Optically rough surfaces were mechanically polished with $0.05 \mu \mathrm{m}$ alumina grit and annealed for $45 \mathrm{~min}$, at $550{ }^{\circ} \mathrm{C}$, in a hydrogen furnace. To remove the outermost distorted/ contaminated lattice layers, the electrode was etched for a few seconds with a $1: 1(\mathrm{v} / \mathrm{v})$ mixture of $40 \% \mathrm{H}_{2} \mathrm{O}_{2}$ and $30 \% \mathrm{NH}_{3}$ and rinsed thoroughly with water, prior to each experiment. Typical $\mathrm{Ag}(111)$ surfaces are formed by large $(\sim 130 \mathrm{~nm})$ terraces limited by step bunches and narrow $(<2 \mathrm{~nm})$ terraces. ${ }^{19}$ Two-dimensional terrace structures correspond to ideally terminated bulk $\mathrm{Ag}(111)$, with an atomic surface density of $1.388 \times 10^{15}$ atoms $\mathrm{cm}^{-2}$ at room temperature ${ }^{32}$ that we define here as one monolayer (1 ML).

2.2. Voltammetry. Voltammetric runs with $\mathrm{Ag}(111)$ working electrodes were carried out at $25^{\circ} \mathrm{C}$ in a conventional glass cell with a platinum counter electrode and a saturated calomel reference electrode utilizing a PAR 373 potentiostat. High-purity chemicals and Milli-Q* water were used to prepare deaerated aqueous $0.1 \mathrm{M} \mathrm{NaOH}+50 \mu \mathrm{M} \mathrm{Na} 2 \mathrm{~S}, 0.1 \mathrm{M} \mathrm{NaOH}+50 \mu \mathrm{M} \mathrm{TU}$, $0.1 \mathrm{M} \mathrm{NaClO}_{4}+50 \mu \mathrm{M} \mathrm{TU}$, and $0.1 \mathrm{M} \mathrm{NaOH}+50 \mu \mathrm{M}$ ETU solutions. Fresh solutions were used in all cases due to the reactivity of sulfur- and TU-based compounds in water. All potentials in the text are referred to the SCE scale.

2.3. STM Imaging. In situ STM images were taken at $25^{\circ} \mathrm{C}$ with a Digital Instruments Inc. Nanoscope III ECSTM. Images were plane removed and flattened using commercial imageprocessing software to correct for tilt and bow. Commercial and scissors-snipped $90 \% \mathrm{Pt}-10 \%$ Ir tips were coated with Apiezon wax for electrochemical observations.

The STM electrochemical cell was made of Kel-F. It consisted of the $\mathrm{Ag}(111)$ single-crystal working electrode, a large-area platinum counter electrode, and a palladium/hydrogen reference electrode, although all values of $E$ in the text are given in the SCE scale. Samples were first immersed at open circuit potential $\left(E_{\text {ocp }}\right)$ in aqueous $0.1 \mathrm{M} \mathrm{NaOH}+50 \mu \mathrm{M}\left(\mathrm{Na}_{2} \mathrm{~S}\right.$, TU, or ETU) solutions. Subsequently, the potential was swept downward until the potential range of net hydrogen evolution (her) was reached and stepped upward to a holding potential $E_{\mathrm{h}}>E_{\mathrm{A} 1}$, the potential of the first electroadsorption peak, where samples were finally

(32) CRC Handbook of Chemistry and Physics, 57th ed.; Weast, $\mathrm{R}$ C., Ed.; CRC Press: Boca Raton, FL, 1976-1977; p F216. 


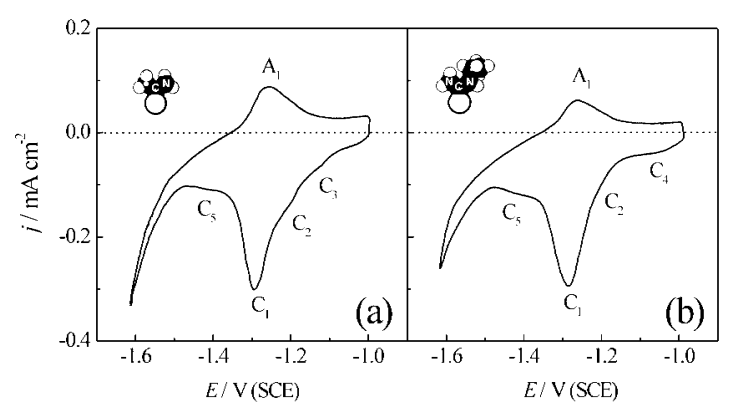

Figure 1. Cyclic voltammograms of $\mathrm{Ag}(111)$ in aqueous $0.1 \mathrm{M}$ $\mathrm{NaOH}+50 \mu \mathrm{M}$ TU (a) and $0.1 \mathrm{M} \mathrm{NaOH}+50 \mu \mathrm{M}$ ETU (b), $v$ $=0.200 \mathrm{~V} \mathrm{~s}^{-1}, T=300 \mathrm{~K}$, including space-filling models of TU and ETU molecules.

imaged. Alternatively, samples were directly immersed and imaged at $E_{\mathrm{h}}>E_{\mathrm{A} 1}$. Both potential routines used for imaging resulted in the same ordered adsorbate structures and are used indistinctly in this work. Imaging potentials and tunneling conditions are indicated in the respective figure captions.

\section{Results and Discussion}

3.1. Electrochemical Response. Several potentialtime routines were used, changing the holding potential $\left(E_{\mathrm{h}}\right)$ and time $\left(t_{\mathrm{h}}\right)$ and the number of cycles, while keeping the values of the anodic $\left(E_{\mathrm{as}}\right)$ and cathodic $\left(E_{\mathrm{cs}}\right)$ switching potentials constant.

Typical voltammetric responses of $\operatorname{Ag}(111)$ in aqueous $50 \mu \mathrm{m}$ (TU or ETU) $+0.1 \mathrm{M} \mathrm{NaOH}$ at $0.200 \mathrm{~V} \mathrm{~s}^{-1}$ from $E_{\mathrm{cs}} \cong-1.6 \mathrm{~V}$ to $E_{\mathrm{as}} \cong-1.0 \mathrm{~V}$, after first holding the $E_{\mathrm{h}}=$ $-1.5 \mathrm{~V}$ during $5 \mathrm{~min}$, are shown in Figure 1.

The broad anodic current peak $\mathrm{A}_{1}$ at $E_{\mathrm{A} 1}=-1.26 \mathrm{~V}$ and better defined cathodic current peak $\mathrm{C}_{1}$ at $E_{\mathrm{C} 1}=-1.30 \mathrm{~V}$ that are observed in TU-containing solutions (Figure 1a) have been related to the adsorption/desorption of compact hexagonal phases. ${ }^{20}$ The cathodic charge density from peak $\mathrm{C}_{1}$ is $q_{\mathrm{C}} \cong 220 \mu \mathrm{C} \mathrm{\textrm {cm } ^ { - 2 }}$. The slight increase in anodic current observed for $E>-1.0 \mathrm{~V}$, that is, positive of the conjugate pair of peaks $\mathrm{A} 1 / \mathrm{C} 1$, has been assigned to the electro-oxidation of TU yielding formamidine disulfide and other adsorbed sulfur species. ${ }^{20,33}$ The hydrogen evolution reaction (her) is clearly observed upon extending the reverse potential scan to potentials more negative than $E=-1.5 \mathrm{~V}$. Three other cathodic peaks, $\mathrm{C}_{5}, \mathrm{C}_{2}$, and $\mathrm{C}_{3}$, are also insinuated at $E_{\mathrm{C} 5}=-1.42 \mathrm{~V}, E_{\mathrm{C} 2}=-1.20 \mathrm{~V}$, and $E_{\mathrm{C} 3}=-1.13 \mathrm{~V}$, respectively. They will be discussed in more detail further below.

Under comparable conditions, the voltammetric response of $\mathrm{Ag}(111)$ in ETU aqueous solutions (Figure 1b) is quite similar to that depicted in Figure 1a. It exhibits a main pair of peaks $\mathrm{A}_{1} / \mathrm{C}_{1}$ at $E_{\mathrm{A} 1}=-1.26 \mathrm{~V}$ and $E_{\mathrm{C} 1}=$ $-1.28 \mathrm{~V}$, for $\mathrm{A}_{1}$ and $\mathrm{C}_{1}$, respectively; the initiation of her below $E=-1.5 \mathrm{~V}$; and the same cathodic current peak multiplicity $\mathrm{C}_{5}, \mathrm{C}_{2}$, and $\mathrm{C}_{4}$ at $E_{\mathrm{C} 5}=-1.43 \mathrm{~V}, E_{\mathrm{C} 2}=-1.21$ $\mathrm{V}$, and $E_{\mathrm{C} 4}=-1.06 \mathrm{~V}$, respectively. The cathodic charge density from peak $\mathrm{C}_{1}$ is $q_{\mathrm{C} 1} \cong 210 \mu \mathrm{C} \mathrm{\textrm {cm } ^ { - 2 }}$.

For both TU and ETU, the measured $q_{\mathrm{C} 1}$ values are

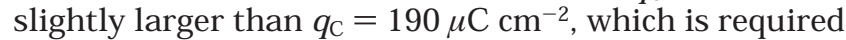
to form the typical alkanethiol ${ }^{34}$ and sulfur ${ }^{27,35} \mathrm{Ag}(111)$ $(\sqrt{ } 7 \times \sqrt{ } 7) \mathrm{R} 19.1^{\circ}$ overlayer structures, assuming a oneelectron charge transfer per molecule. The resulting degree of surface coverage $(\theta)$ is, within experimental error, equal to that estimated from the ideal $q_{\mathrm{C} 1}$ value. However,

(33) Azzaroni, O.; Andreasen, G.; Blum, B.; Salvarezza, R. C.; Arvia A. J. J. Phys. Chem. B 2000, 104, 1395.

(34) Heinz, R.; Rabe, J. P. Langmuir 1995, 11, 506.

(35) Kakiuchi, T.; Usui, H.; Hobara, D.; Yamamoto, M. Langmuir 2002, 18, 5231.

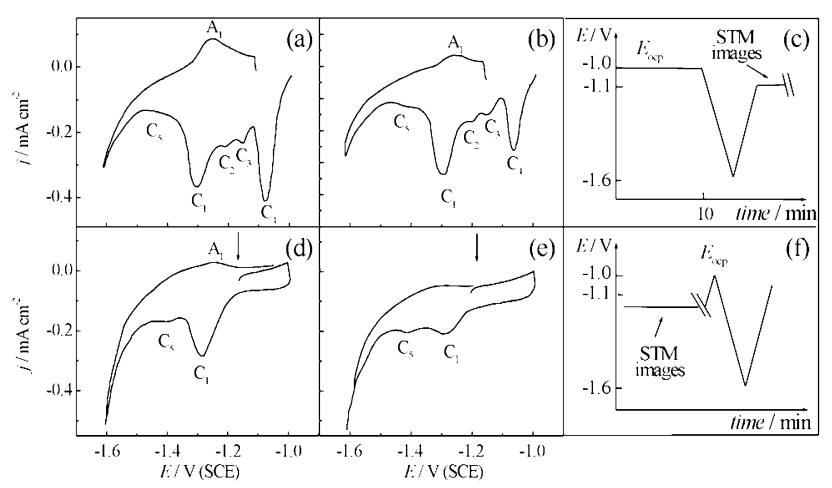

Figure 2. Voltammograms of $\mathrm{Ag}(111)$ in aqueous $0.1 \mathrm{M} \mathrm{NaOH}$ $+50 \mu \mathrm{M}$ TU $(\mathrm{a}, \mathrm{d})$ and $0.1 \mathrm{M} \mathrm{NaOH}+50 \mu \mathrm{M}$ ETU $(\mathrm{b}, \mathrm{e}), v=$ $0.200 \mathrm{~V} \mathrm{~s}^{-1}, T=300 \mathrm{~K}$. The time routines indicated in (c) and (f) were the runs utilized with solutions (a,b) and (c,d), respectively. Arrows indicate the conditions utilized for STM imaging.

several independent concurrent factors such as (i) substrate surface roughness, (ii) adsorbate surface arrangements that are more compressed than in the standard $d_{\mathrm{n}}$ $=0.44 \mathrm{~nm} \operatorname{Ag}(111)-(\sqrt{ } 7 \times \sqrt{ } 7) \mathrm{R} 19.1^{\circ}$ structure, ${ }^{19}$ and (iii) a combination of a semi-infinite linear diffusion of desorbed species with an approximate adsorption isotherm based on the two-dimensional Ising model ${ }^{35}$ would also account for an increased $q_{\mathrm{C} 1}$ value. Therefore, from the $q_{\mathrm{C} 1}$ value alone no definite picture of the structures formed at this potential can be drawn.

Both the peak multiplicity and the relative peak intensities depend markedly on the variables involved in the potential routine, particularly on $E_{\mathrm{h}}$ and $t_{\mathrm{h}}$, as would be expected for a complex surface electrochemical kinetics at $\mathrm{Ag}(111)$. Thus, the electrodesorption voltammograms for TU (Figure 2a) and ETU (Figure $2 \mathrm{~b}$ ) recorded after setting $E_{\mathrm{h}}$ at the open circuit potential $\left(E_{\text {ocp }}\right)$ for $t_{\mathrm{h}}=10$ min (Figure 2c) show a large cathodic peak $\mathrm{C}_{4}$ at $E_{\mathrm{C} 4} \cong$ $-1.07 \mathrm{~V}$ and a better resolution of peaks $\mathrm{C}_{3}$ and $\mathrm{C}_{2}$ than in Figure 1. When $E_{\mathrm{h}}$ is set slightly more positive than the potential of peak $A_{1}$ (Figure $2 f$ ), only peaks $C_{1}$ and $C_{5}$ (Figure 2d,e) related to those species that are formed in the potential range of wave $\mathrm{A}_{1}$ are observed, whereas peaks $\mathrm{C}_{4}, \mathrm{C}_{3}$, and $\mathrm{C}_{2}$ are absent. In this case, the values of $q_{\mathrm{C}}$ derived from peaks $\mathrm{C}_{1}$ and $\mathrm{C}_{5}$ are $q_{\mathrm{C} 1}=120 \mu \mathrm{C} \mathrm{cm}^{-2}$ and $q_{\mathrm{C} 5} \cong 20 \mu \mathrm{C} \mathrm{cm}^{-2}$ for TU and $q_{\mathrm{C} 1}=70 \mu \mathrm{C} \mathrm{cm}^{-2}$ and $q_{\mathrm{C} 5} \cong$

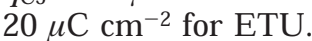

The peak multiplicity observed during electrodesorption of TU and ETU has also been observed in cyclic voltammograms of $\operatorname{Ag}(111)$ electrodes in slightly more concentrated sulfide solutions. ${ }^{26,27,30,36,37}$ For slightly more positive anodic switching potential, $E_{\text {as }}$, the conjugate peak $\mathrm{A}_{4}$ is also resolved. ${ }^{26,27,30,36,37}$ Depending on either the potential routine, ${ }^{27}$ the sulfur-containing species concentration, or both, the voltammetric charge of peak $\mathrm{C}_{4}$ relative to that of $\mathrm{C}_{1}$ has been shown to vary significantly. ${ }^{26}$ For TU, the value of $q_{\mathrm{C} 4}$ increases continuously with $t_{\mathrm{h}}$ at $E_{\text {ocp }}$, largely exceeding the $q_{C}$ value expected for a single monolayer, suggesting that this peak corresponds to the electroreduction of a multilayer. ${ }^{19}$

Holding $E_{\mathrm{h}}$ at highly reducing values prior to cycling in sulfide or TU-containing solutions (Figure 3) results in a single electroadsorption-desorption pair of peaks $A_{1} / C_{1}$

(36) Hatchet, D. W.; White, H. S. J. Phys. Chem. 1996, 100, 9854.

(37) Foresti, M. L.; Innocenti, M.; Forni, F.; Guidelli, R. Langmuir 1998, 14, 7008 . 


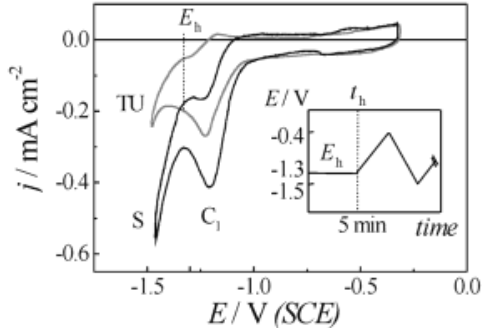

Figure 3. Cyclic voltammograms of $\operatorname{Ag}(111)$ in aqueous $0.1 \mathrm{M}$ $\mathrm{NaOH}+50 \mu \mathrm{M} \mathrm{Na} 2 \mathrm{~S}$ (black) and $0.1 \mathrm{M} \mathrm{NaOH}+50 \mu \mathrm{M}$ TU (gray) solutions, $v=0.100 \mathrm{~V} \mathrm{~s}^{-1}, T=300 \mathrm{~K}$. The inset shows the potential routine.

at $-1.2 \mathrm{~V}$. Holding the potential positive with respect to the potential of peak $\mathrm{A}_{4}{ }^{26}$ resulted in the same peak multiplicity as that shown in Figure 2a,b, but only for few cycles. ${ }^{27}$ The peak position and full width at half-maximum of cathodic peak $C_{1}$ are again comparable with those observed for TU, ETU, and short-chain alkanethiol adsorption on $\operatorname{Ag}(111)^{14,29}$ and $\operatorname{Au}(111){ }^{35}$

Alternatively, alkanethiol desorption from rough/ stepped $\mathrm{Au}(111)$ surfaces $^{38}$ and desorption of sulfurcontaining molecules from $\operatorname{Ag}(110)^{36}$ result in the appearance of cathodic peak $C_{5}$ at the expense of peak $C_{1}$. Therefore, while the potential routine strongly affects the cathodic charge of peak $\mathrm{C}_{4}$, and to a lesser extent the cathodic charge of peak $\mathrm{C}_{1}$, the latter is also visibly affected by surface topography.

Similar results are obtained for voltammograms of $\mathrm{Ag}(111)$ in aqueous $50 \mu \mathrm{M} \mathrm{TU}+0.1 \mathrm{M} \mathrm{NaClO}_{4}$ solution run from 50 to $0.25 \mathrm{~V} \mathrm{~s}^{-1}$, except for a systematic shift of all peak potentials by ca. $0.09 \mathrm{~V}$, so that, for example, $E_{\mathrm{C} 1}$ $=-1.21 \mathrm{~V}$. This shift indicates that both the electroadsorption and electrodesorption reactions are $\mathrm{pH}$ dependent, as these processes involve a proton transfer. The canonical form of TU in solution ${ }^{13}$ follows a thioureate adsorbate on $\mathrm{Ag}(111)$ as concluded from X-ray photoelectron spectroscopy data of TU adsorbates on $\operatorname{Ag}(111)$ surfaces. ${ }^{20}$

In summary, voltammetric responses of S, TU, ETU, and alkanethiols on $\mathrm{Ag}(111)$ in both alkaline and neutral solutions are all quite similar. Despite these similarities, adlayer structural assignments associated with these peaks differ considerably among authors. ${ }^{20,14,26-29}$ However, it should be borne in mind that cyclic voltammetry is only indicative of the chemical reactions accessible at each potential window under the specific conditions of the potential routine applied to the electrochemical interface. In particular, the charge density of the pair of peaks $A_{1} / C_{1}$ has been shown to depend on both the holding potential and time at $E_{\mathrm{h}}>E_{\mathrm{A} 1},{ }^{19}$ but not on the sulfide ${ }^{26}$ or $\mathrm{TU}^{19}$ concentrations. Thus, peak $\mathrm{A}_{1}$ should be related to the film structure occurring at the early stages of its formation. This bears a direct relation with STM imaging run at constant $E$. To relate the conjugate pair of peaks $\mathrm{A}_{1} / \mathrm{C}_{1}$ to a definite reaction and structure, STM imaging of $\mathrm{Ag}(111)$ in ETU-, TU-, and S-containing solutions was performed at potentials positive with respect to the potential of peak $A_{1}$, after first cycling through the potential range of her, that is, from $E_{\text {ocp }}$ to $E_{\mathrm{cs}}=-1.5 \mathrm{~V}$ and backward to $E_{\mathrm{h}}$ slightly positive of $E_{\mathrm{A} 1}$.

3.2. In Situ STM Imaging. Figure 4 displays in situ STM images of ETU on Ag(111). All images have the same magnification, to facilitate visual comparison. An Ag(111)$(\sqrt{ } 7 \times \sqrt{ } 7)$-ETU hexagonal superstructure with $d_{\mathrm{s}}=0.78$

(38) Walkzak, M. M.; Alves, C. A.; Lamp, B. D.; Porter, M. D. J. Electroanal. Chem. 1995, 396, 103.

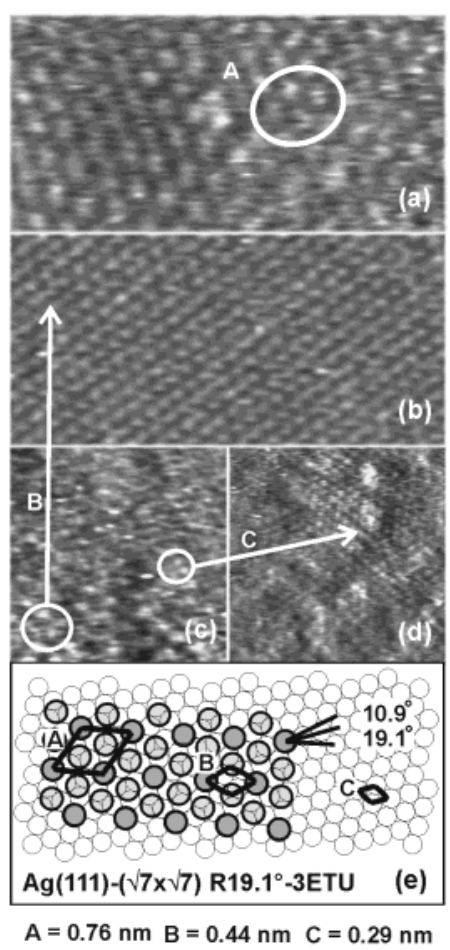

Figure 4. In situ STM images of $\mathrm{Ag}(111)$ in aqueous $0.1 \mathrm{M}$ $\mathrm{NaOH}+50 \mu \mathrm{M}$ ETU solution at $E_{\mathrm{h}}=-1.285 \mathrm{~V}$ versus SCE; $E_{\text {bias }}=560 \mathrm{mV}$, and $I_{\text {tip }}=7.0 \mathrm{nA}$. (a,b) $11.0 \times 5.5 \mathrm{~nm}^{2}$ image, $(\mathrm{c}, \mathrm{d}) 5.5 \times 5.5 \mathrm{~nm}^{2}$ image. (e) Scheme of the $\operatorname{Ag}(111)$ $(\sqrt{ } 7 \times \sqrt{ } 7)$ R $19.1^{\circ}$-ETU superstructure (A) and molecular array (B). Regions with $d_{\mathrm{Ag}}=0.29 \mathrm{~nm}(\mathrm{C})$ are associated with bulkterminated $\mathrm{Ag}(111)$. Silver atoms and ETU molecules are drawn as light and dark circles, respectively.

$\pm 0.03 \mathrm{~nm}$ (Figure $4 \mathrm{a}, \mathrm{A}$ ) is resolved into 3 ETU molecules with $d_{\mathrm{n}}=0.44 \pm 0.02 \mathrm{~nm}$ and, ideally, a calculated degree of surface coverage $\theta=0.43 \mathrm{ML}$ (Figure $4 \mathrm{~b}, \mathrm{c}, \mathrm{B}$ ). In regions where $\theta<0.43 \mathrm{ML}$, the $\mathrm{Ag}(111)$ substrate imaged (Figure 4c,d, C) corresponds to either the naked Ag(111) substrate or dilute/disordered ETU-covered regions. Preferential imaging of the metal substrate is common when dilute sulfur adlayers are present (cf. ref 39). A scheme of the ordered substrate and adsorbate structures is shown in Figure 4e. Differences in size and angular orientation of ETU supercell A $\left(d_{\mathrm{s}}=0.76 \mathrm{~nm}, \alpha=19.1^{\circ}\right)$ and molecular array $\mathrm{B}\left(d_{\mathrm{n}}=0.44 \mathrm{~nm}, \alpha=10.9^{\circ}\right)$ with respect to the $\mathrm{Ag}(111)$ substrate cell $\mathrm{C}\left(d_{\mathrm{Ag}}=0.29 \mathrm{~nm}\right)$ are highlighted.

The $\operatorname{Ag}(111)-(\sqrt{ } 7 \times \sqrt{ } 7)$-ETU structure is stable for ca. $3 \mathrm{~h}$ at $E=-1.285 \mathrm{~V}$. It is the only ordered structure observed for ETU/Ag(111) at these potentials. Shifting $E$ in the positive direction as far as $-0.5 \mathrm{~V}$ results in no new structures in STM images. The same adlayer structure has been reported for sulfur, ${ }^{27,34,37,40,41}$ alkanethiol, ${ }^{34,42-44}$ and TU ${ }^{19,20}$ adsorption on $\mathrm{Ag}(111)$. For both $\mathrm{S}^{27}$ and TU, ${ }^{19,20}$ however, more compact adsorbate arrangements have also been reported. In the case of self-assembled alkanethiol monolayers on $\operatorname{Ag}(111)$, the $\operatorname{Ag}(111)-(\sqrt{ } 7 \times \sqrt{ } 7)$-thiol structure increases from $d_{\mathrm{n}} \cong 0.44 \mathrm{~nm}$ to $d_{\mathrm{n}} \cong 0.48 \mathrm{~nm}$ with

(39) Poirier, G. E.; Fitts, W. P.; White, J. M. Langmuir 2001, 17, 1176

(40) Schwaha, K.; Spencer, N. D.; Lambert, R. M. Surf. Sci. 1979, 81, 273.

(41) Rovida, G.; Pratesi, F. Surf. Sci. 1981, 104, 609.

(42) Fenter, P.; Eisenberger, P.; Li, J.; Camillone, N., III; Bernasek, S.; Scoles, G.; Ramanarayanan, T. A.; Liang, K. S. Langmuir 1991, 7 , 2013

(43) Dhirani, A.; Hines, M. A.; Fisher, A. J.; Ismail, O.; GuyotSionnest, P. Langmuir 1995, 11, 2609.

(44) Rieley, H.; Kendall, G. K. Langmuir 1999, 15, 8856. 


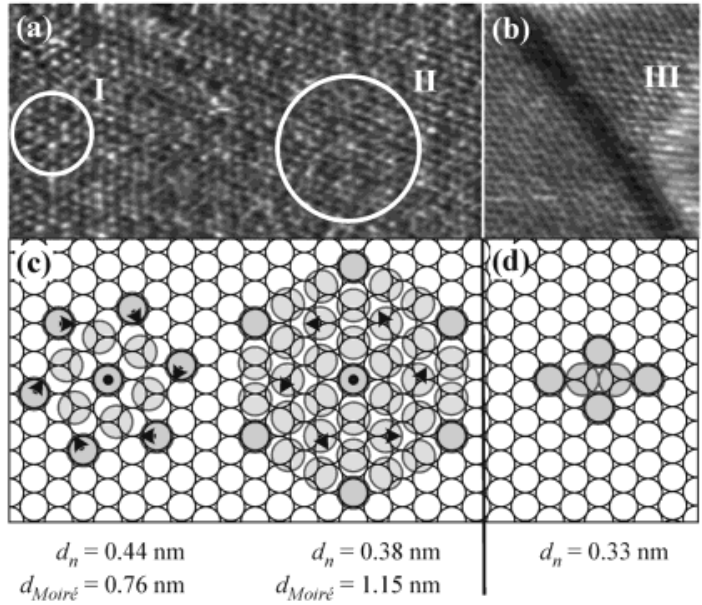

Figure 5. In situ STM images of $\mathrm{Ag}(111)$ in aqueous $0.1 \mathrm{M}$ $\mathrm{NaOH}+50 \mu \mathrm{M}$ TU solution at $E_{\mathrm{h}}=-1.185 \mathrm{~V}(\mathrm{SCE}) ; E_{\text {bias }}=$ $402 \mathrm{mV}$, and $I_{\text {tip }}=17.6 \mathrm{nA}$. (a) $15.0 \times 7.5 \mathrm{~nm}^{2}$ image; (b) 6.9 $\times 7.5 \mathrm{~nm}^{2}$ image; (c,d) scheme of adlayer structures. Light circles are Ag atoms, and dark circles, TU molecules. The supercell giving rise to the observed Moiré pattern is highlighted by shadowing the TU molecule adsorbed on coincidence top sites.

increasing chain length. ${ }^{34,42-44}$ A detailed interplay of adsorbate-substrate and pendant hydrocarbon chainchain interactions is presumably responsible for the adsorbate structures observed. This fact is associated with a gradual shift in the position of the voltammetric peak with increasing chain length. ${ }^{14,28,29}$ The absence of any observable shift in the position of the ETU voltammetric peak with respect to TU, combined with ETU molecular dimensions, hints at the possibility of combined steric effects and adsorbate-substrate interactions as being the main cause accountable for the observed intermolecular ETU spacing in self-assemblies formed on $\mathrm{Ag}(111)$.

Given the extremely similar voltammetric responses of $\mathrm{Ag}(111)$ in TU and ETU aqueous solutions under a wide variety of potential routines, it is interesting to determine whether TU structures on $\mathrm{Ag}(111)$ bear any resemblance to those observed by electroadsorbing ETU on $\operatorname{Ag}(111)$, under comparable conditions.

Figure 5 shows molecular resolution images of TU adsorbed on $\operatorname{Ag}(111)$ at $E=-1.185 \mathrm{~V}$. As for ETU, the $\operatorname{Ag}(111)-(\sqrt{ } 7 \times \sqrt{ } 7) \mathrm{R} 19.1^{\circ}$ hexagonal structure with $d_{\mathrm{n}}=$ $0.44 \mathrm{~nm}$ is observed. However, for TU, a gradual compression from $d_{\mathrm{n}}=0.44 \pm 0.02 \mathrm{~nm}$ (Figure 5a, I) to $d_{\mathrm{n}}=$ $0.38 \pm 0.02 \mathrm{~nm}$ (Figure 5a, II) is imaged. The most compact structure observed for TU/Ag(111), ${ }^{20}$ with $d_{\mathrm{n}}=0.33 \pm$ $0.02 \mathrm{~nm}$ (Figure 5b, III), is imaged after holding the potential for $t_{\mathrm{h}} \sim 20 \mathrm{~min}$ at $E_{\mathrm{h}}=-1.185 \mathrm{~V}$. The latter is stabilized by hydrogen bonding. ${ }^{10,33}$ Schematic drawings of molecular arrangements giving rise to the same symmetries are depicted in Figure 5c,d. Arrows in Figure $5 \mathrm{c}$ show a collective molecular rotation/displacement connecting both structures. Hexagonal TU arrays with $d_{\mathrm{n}}$ $=0.44$ and $d_{\mathrm{n}}=0.38 \mathrm{~nm}$ have also been imaged in air after short (10-20 s) immersions in $0.05 \mathrm{mM}$ TU solutions at $E_{\text {oсp. }} \cdot{ }^{19}$ Compact $d_{\mathrm{n}}=0.33 \mathrm{~nm}$ hexagonal arrays, that have also been observed following TU adsorption on $\mathrm{Au}(111),{ }^{33}$ could only be imaged in situ in the case of Ag(111). Hence, combining electrochemical and STM results, we can conclude the occurrence of slow assemblycompression processes involving several minutes. The fact that the rate of these processes is time-potential-window dependent is supported by the space-time coexistence of these surface structures.

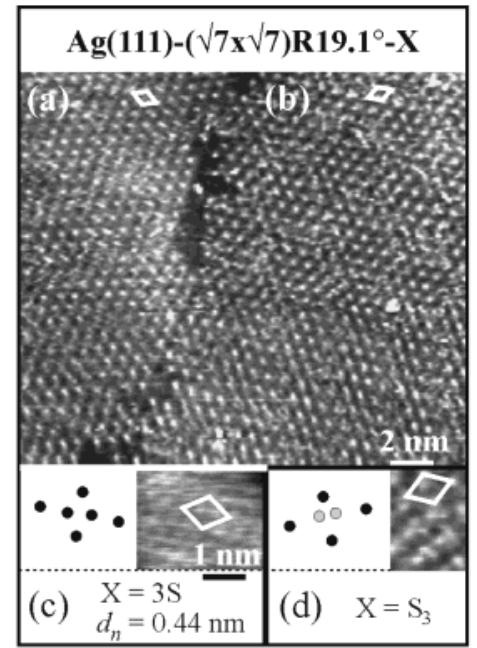

Figure 6. In situ STM images of $\mathrm{Ag}(111)$ in aqueous $0.1 \mathrm{M}$ $\mathrm{NaOH}+50 \mu \mathrm{M} \mathrm{Na} 2 \mathrm{~S}$ at $(\mathrm{a}, \mathrm{b}, \mathrm{d}) E_{\mathrm{h}}=-0.85 \mathrm{~V}, E_{\text {bias }}=0.370 \mathrm{~V}$, and $I_{\text {tip }}=19 \mathrm{nA}$; (c) $E_{\mathrm{h}}=-1.0 \mathrm{~V}, E_{\text {bias }}=0.580 \mathrm{~V}$, and $I_{\text {tip }}=28$ nA. Mirrored S-trimer $(\sqrt{ } 7 \times \sqrt{ } 7)$ R $19.1^{\circ}$ domains $(a, b)$ are separated by a S-deficient boundary. The scale markers are 2 $\mathrm{nm}(\mathrm{a}, \mathrm{b})$ and $1 \mathrm{~nm}(\mathrm{c}, \mathrm{d})$. The $(\sqrt{7} \times \sqrt{ } 7) \mathrm{R} 19.1^{\circ}$ supercell is indicated in all four panels, together with scheme drawings $(\mathrm{c}, \mathrm{d})$ of associated S structures.

The degree of surface coverage of the three ordered hexagonal arrays (I, II, and III) depicted in Figure 5, determined by dividing the number of TU molecules by the number of $\mathrm{Ag}(111)$ surface atoms in each respective unit cell (Figure $5 \mathrm{c}, \mathrm{d}$ ), is $\theta_{\mathrm{I}}=3 / 7=0.43 \mathrm{ML}, \theta_{\mathrm{II}}=9 / 16$ $=0.56 \mathrm{ML}$, and $\theta_{\mathrm{III}}=3 / 4=0.75 \mathrm{ML}$. These ordered arrays coexist with dilute/disordered arrays having smaller $\theta$ values. The intermediate value $\theta=0.44 \mathrm{ML}$ that was determined from the corresponding $q_{\mathrm{C} 1}$ value (Figure $1 \mathrm{a}$ ) is consistent with the space-time coexistence of dilute/ disordered and ordered TU array domains on the same $\mathrm{Ag}(111)$ substrate. Notwithstanding, several other independent concurrent effects can also influence $q_{\mathrm{C} 1}$, and therefore $\theta$, as indicated in section 3.1.

Considering that all three ordered TU-Ag(111) structures electrodesorb at $C_{1}$ and taking all concurrent factors affecting the value of $q_{\mathrm{C} 1}$ into account, reliable average $\theta$ values and percentiles of each ordered structure cannot be determined from our global $q_{\mathrm{C}}$ measurements combined with local STM images. However, further insight on the substrate-adsorbate interaction operating at $\mathrm{C}_{1}$ can be gained by comparing the electrosorption of TU with the electrosorption of S-containing molecules such as ETU and sulfide/sulfur species.

The voltammetric response of sulfur-containing residues (Figure 3) has already been shown to be similar to those of TU and ETU. Ordered sulfur arrays on $\mathrm{Ag}(111)$ (Figure 6 ) include the conventional equi-spaced $d_{\mathrm{n}}=0.44 \mathrm{~nm}$ $\operatorname{Ag}(111)-(\sqrt{ } 7 \times \sqrt{ } 7) R 19.1^{\circ}-3 S$ (Figure $\left.6 \mathrm{c}\right)^{27,34,40,41}$ and $\operatorname{Ag}(111)$ $(\sqrt{ } 7 \times \sqrt{ } 7) \mathrm{R} 19.1^{\circ}-\mathrm{S}_{3}$ structures (Figure 6a,b,d), ${ }^{27}$ depending again on the imaging potential and the adsorption time. Both $\operatorname{Ag}(111)-(\sqrt{7} \times \sqrt{7}) \mathrm{R} 19.1^{\circ}$ domains equivalent by symmetry are present in Figure 6a,b, with an S-deficient boundary between mirrored domains. While sulfur and methanethiol adsorption on $\mathrm{Cu}(111)^{45}$ and $\mathrm{Ni}(111)^{46}$ have been observed to induce pseudo-square reconstruction involving substrate atom displacement, this possibility cannot be considered here, since the 6-fold substrate surface symmetry is conserved during our experiments.

(45) Driver, S. M.; Woodruff, D. P. Surf. Sci. 2000, 457, 11

(46) Fisher, C. J.; Woodruff, D. P.; Jones, R. G.; Cowie, B. C. C.; Formoso, V. Surf. Sci. 2002, 496, 73. 
Scheme 1. Potential-Time-Dependent SAMs, Intermolecular Spacing, and Dominant Interactions for S, TU, and ETU Electroadsorbed on $\mathrm{Ag}(111)$ at ca. $-1.2 \mathrm{~V}$ versus SCE

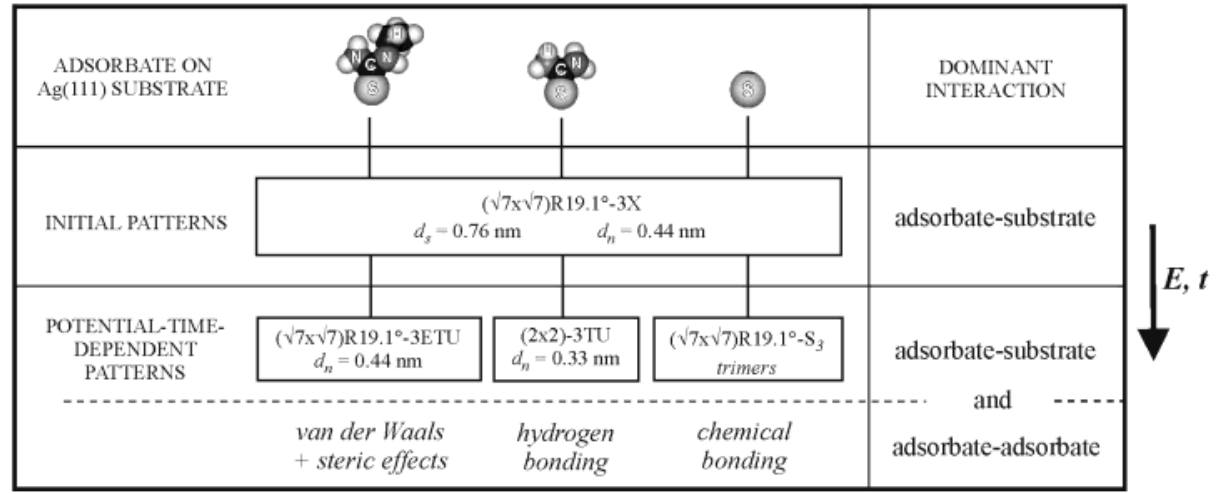

Table 1. Voltammetric Electroadsorption $\left(E_{\mathrm{A} 1}\right)$ and Electrodesorption $\left(E_{\mathrm{C} 1}\right)$ Peak Potentials and Adsorption Energy Difference ( $\left.\Delta E_{\text {ads }}\right)$ for TU and ETU Adsorbates Produced on Ag(111) and Au(111) from $50 \mu M$ TU- and $50 \mu M$ ETU-Containing Neutral and Alkaline Aqueous Solutions ${ }^{a}$

\begin{tabular}{|c|c|c|c|c|c|c|c|}
\hline & \multicolumn{5}{|c|}{ TU on the following substrates } & \multicolumn{2}{|c|}{ ETU on the following substrates } \\
\hline & $\operatorname{Ag}(111)$ & $\mathrm{Au}(111)$ & $\operatorname{Ag}(111)$ & $\mathrm{Au}(111)$ & $\mathrm{Au}(111)$ & $\operatorname{Ag}(111)$ & $\mathrm{Au}(111)$ \\
\hline base electrolyte & \multicolumn{2}{|c|}{$\mathrm{NaOH}$} & \multicolumn{2}{|c|}{$\mathrm{NaClO}_{4}$} & $\mathrm{H}_{2} \mathrm{SO}_{4}$ & $\mathrm{NaOH}$ & $\mathrm{H}_{2} \mathrm{SO}_{4}$ \\
\hline concentration/M & 0.1 & 0.1 & 0.1 & 0.05 & 0.5 & 0.1 & 0.5 \\
\hline$v / \mathrm{V} \mathrm{s}^{-1}$ & 0.200 & 0.050 & 0.150 & 0.100 & $\mathrm{TMTPV}^{b}$ & 0.200 & $\mathrm{TMTPV}^{b}$ \\
\hline$E_{\mathrm{C} 1} / \mathrm{V}$ & -1.30 & $-0.92^{c}$ & -1.21 & $-0.84^{d}$ & $-0.34^{e}$ & -1.28 & $-0.34^{e}$ \\
\hline$E_{\mathrm{A} 1} / \mathrm{V}$ & -1.26 & & -1.17 & $-0.81^{d}$ & $-0.34^{e}$ & -1.26 & $-0.34^{e}$ \\
\hline$\Delta E_{\text {ads }} / \mathrm{kJ} \mathrm{mol}{ }^{-1}$ & \multicolumn{2}{|c|}{$40 \pm 1^{f}$} & \multicolumn{3}{|c|}{$40 \pm 1^{f}$} & & \\
\hline
\end{tabular}

${ }^{a}$ In aqueous sulfuric acid, the TU and ETU concentrations are $1 \mathrm{mM}$. In the estimation of errors in $\Delta E_{\text {ads, }}$ only errors in peak potentials are considered. $T=300 \mathrm{~K} .{ }^{b}$ TMTPV: triangularly modulated triangular potential voltammetry. ${ }^{c} \mathrm{H}$. Martin, private communication. ${ }^{d}$ Reference 33. ${ }^{e}$ A. Bolzan, private communication. ${ }^{f}$ From eq 4.

In summary, an initial $d_{\mathrm{n}}=0.44 \mathrm{~nm}$ hexagonal structure is common to all species adsorbed (Scheme 1). The simultaneous adsorption on different high-symmetry sites is facilitated by the small energy cost in moving from hollow to atop sites on $\operatorname{Ag}(111) .{ }^{47}$ For TU and S, this structure evolves into more condensed substructures, as a result of attractive interaction between molecules..$^{5,10,33}$ A single electroadsorption wave at about $-1.2 \mathrm{~V}$ is associated with this adsorption/compaction process. The electroadsorption charge density determined from the anodic wave increases as the surface coverage is increased; however, the peak potential remains the same. This means that the adsorbate-substrate interaction remains almost constant. Hence, one can consider that the adsorbatesubstrate interaction plays a key role in determining the surface structure of TU and TU derivatives on silver surfaces. The same would hold true for gold surfaces given the structural and voltammetric similarities encountered. This will be discussed in more detail below.

3.3. Evaluation of Sulfur-Containing AdsorbateAg(111) and - Au(111) Interactions. TU electrosorption cyclic voltammetry on both $\mathrm{Ag}(111)$ and $\mathrm{Au}(111)$ is characterized by the main pair of peaks $A_{1}$ (electroadsorption) $/ \mathrm{C}_{1}$ (electrodesorption). ${ }^{10,20,33}$ In neutral media, at room temperature, voltammograms run in the range $0.050 \mathrm{~V} \mathrm{~s}^{-1} \leq V \leq 0.250 \mathrm{~V} \mathrm{~s}^{-1}$ exhibit peak potentials at $E_{\mathrm{C} 1}=-1.21 \mathrm{~V}$ and $E_{\mathrm{A} 1}=-1.17 \mathrm{~V}$ for silver (111), and $E_{\mathrm{C} 1}$ $=-0.83 \mathrm{~V}$ and $E_{\mathrm{A} 1}=-0.81 \mathrm{~V}$ for gold (111) (Table 1). ${ }^{48}$ In alkaline media, these peaks are shifted by approximately $0.08 \mathrm{~V}$ in the negative direction (Table 1). Peak positions for ETU in alkaline (Figure 1) (Table 1) and acidic (Table 1$)^{49}$ solutions appear at the same potentials as for TU (Table 1) ${ }^{50}$ in the respective media.

(47) Sellers, H.; Ulman, A.; Shnidman, Y.; Eilers, J. E. J. Am. Chem. Soc. 1993, 115, 9389.

(48) Martín, H. Private communication. Unpublished results.

(49) Bolzan, A. E.; Piatti, R. C. V.; Arvia, A. J. In preparation.
For the experimental conditions described in Figure 1, the specific anodic $\left(q_{\mathrm{A}}\right)$ and cathodic $\left(q_{\mathrm{C}}\right)$ charges involved in those processes are slightly larger than those expected for either TU or ETU monolayers involving a single electron transfer per adsorbed molecule and $d_{\mathrm{n}}=0.44$ $\mathrm{nm}$, and decrease with the number and size of substituents in the TU molecules, although the ratio $q_{\mathrm{A}} / q_{\mathrm{C}}$ is close to 1 in both cases.

These results indicate the TU electrosorption on $\mathrm{Ag}(111)$ and $\mathrm{Au}(111)$ approaches the behavior of a reversible surface electrochemical process, as has been demonstrated for $\mathrm{Au}(111)$ by triangularly modulated triangular potential scanning voltammetry for $\mathrm{Au}(111)-\mathrm{TU}^{50}$ and by infrared reflectance spectroscopy and conventional electrochemical techniques for $\mathrm{Au}(111)$ - tetramethylthiourea. ${ }^{51}$ Accordingly, let us relate the single voltammetric electroadsorption/electrodesorption cycle to the tautomeric forms of solvated TU and the solvent-metal (Me) surface interactions as follows,

$$
\left[\left(\mathrm{H}_{2} \mathrm{~N}\right)_{2}-\mathrm{C}=\mathrm{S}\right](\text { solv }) \Leftrightarrow\left[\left(\mathrm{H}_{2} \mathrm{~N}\right)(\mathrm{HN}=\mathrm{C}-\mathrm{S}-\mathrm{H})\right](\text { solv })
$$

and

$$
\mathrm{Me}+\text { solv } \Leftrightarrow \mathrm{Me}(\text { solv })+\Delta \text { solv }
$$

where solv stands for solvent molecules in solution and (solv) indicates either solvated adsorbates or solventmetal interactions, neglecting the corresponding stoichiometries.

During the anodic voltammetric scan, TU adsorption on the Me as the canonical form of the molecule is favored. ${ }^{20}$

(50) Bolzan, A. E.; Piatti, R. C. V.; Arvia, A. J. J. Electroanal. Chem., in press.

(51) Port, S. N.; Horswell, S. L.; Raval, R.; Schiffrin, D. J. Langmuir $1996,12,5934$. 
For a Me negatively charged with respect to the solution $\left(E<E_{\mathrm{pzc}}\right)$, the adsorption can be explained by the equilibrium

$$
\begin{aligned}
& \left(2 \mathrm{e}^{-}\right) \mathrm{Me}(\text { solv })+\left[\left(\mathrm{H}_{2} \mathrm{~N}\right)_{2}-\mathrm{C}=\mathrm{S}\right](\text { solv }) \leftrightarrow \\
& \left(2 \mathrm{e}^{-}\right) \mathrm{Me}-\left[\left(\mathrm{S}-\mathrm{C}=\mathrm{NH}_{2}\right)\left(\mathrm{NH}_{2}\right)\right]^{*}(\mathrm{ad})
\end{aligned}
$$

where the $\left(^{*}\right)$ denotes a reordered TU adsorbate intermediate that participates in the following fast electron transfer,

$$
\begin{aligned}
& \left.\left(2 \mathrm{e}^{-}\right) \mathrm{Me}-\left[\mathrm{S}-\mathrm{C}=\mathrm{NH}_{2}\right)\left(\mathrm{NH}_{2}\right)\right]^{*}(\mathrm{ad}) \Leftrightarrow \\
& \left.\left(\mathrm{e}^{-}\right) \mathrm{Me}-[\mathrm{S}-\mathrm{C}=\mathrm{NH})\left(\mathrm{NH}_{2}\right)\right](\mathrm{ad})+\mathrm{H}^{+}(\text {solv })+\mathrm{e}^{-}+
\end{aligned}
$$$$
\Delta \text { solv (2A) }
$$

in which electroadsorbed TU is formed. Stage 2A is accompanied both by TU deprotonation that stabilizes the canonical molecular adsorbate structure and by a local solvation change. For the case of $\mathrm{Ag}(111)$ and $\mathrm{Au}(111)$, TU electroadsorption involves a competitive adsorption on the negatively charged metal surfaces as, at $298 \mathrm{~K}$, $E_{\mathrm{pzc}}(\operatorname{Ag}(111))=-0.722 \mathrm{~V}$ in sodium sulfate and -0.932 $\mathrm{V}$ in sodium fluoride ${ }^{52}$ and $E_{\mathrm{pzc}}(\mathrm{Au}(111))=0.268 \mathrm{~V}$ in sodium fluoride. ${ }^{53}$ The value of $E_{\mathrm{pzc}}(\mathrm{Ag})$ in sodium sulfate is independent of $\mathrm{pH}$ in the range of $3.4-12 .^{54}$

For the TU electrodesorption that occurs during the reverse potential scan, the process starts by a fast electron transfer yielding adsorbed thioureate,

$$
\begin{aligned}
& \left.\left(2 \mathrm{e}^{-}\right) \mathrm{Me}-[\mathrm{S}-\mathrm{C}=\mathrm{NH})\left(\mathrm{NH}_{2}\right)\right](\mathrm{ad}) \Leftrightarrow \\
& \left.\left(1 \mathrm{e}^{-}\right) \mathrm{Me}-\left\{[\mathrm{S}-\mathrm{C}=\mathrm{NH})\left(\mathrm{NH}_{2}\right)\right]^{-}\right\}(\mathrm{ad})
\end{aligned}
$$

Reaction 1D is followed by the solvolysis detachment of adsorbed thiourate to solvated thiourea,

$$
\begin{array}{r}
\left(1 \mathrm{e}^{-}\right) \mathrm{Me}-\left\{\left[(\mathrm{S}-\mathrm{C}=\mathrm{NH})\left(\mathrm{NH}_{2}\right)\right]^{-}\right\}(\mathrm{ad}) \leftrightarrow \\
{\left[\left(\mathrm{H}_{2} \mathrm{~N}\right)(\mathrm{HN}=\mathrm{C}-\mathrm{S}-\mathrm{H})\right](\text { solv })+\left(\mathrm{e}^{-}\right) \mathrm{Me}(\text { solv })+} \\
\mathrm{OH}^{-}(\text {solv })+\Delta \text { solv }
\end{array}
$$

and the solvated product in the solution participates in equilibrium 1S. Hence, the complete cycle at the negatively charged metal surface is represented by the following overall equilibrium,

$$
\begin{aligned}
& \left(2 \mathrm{e}^{-}\right) \mathrm{Me}(\text { solv })+\left[\left(\mathrm{H}_{2} \mathrm{~N}\right)_{2}-\mathrm{C}=\mathrm{S}\right](\text { solv }) \Leftrightarrow \\
& \left.\left(1 \mathrm{e}^{-}\right) \mathrm{Me}-[\mathrm{S}-\mathrm{C}=\mathrm{NH})\left(\mathrm{NH}_{2}\right)\right](\mathrm{ad})+\mathrm{H}^{+}(\text {solv })+\mathrm{e}^{-}+
\end{aligned}
$$

$\Delta$ solv (3)

For a reversible electroadsorption $\left(\Delta G_{\text {ads }}\right) /$ electrodesorption $\left(\Delta G_{\mathrm{des}}\right)$ cycle, each electrosorption free energy change $\Delta G_{\text {ads }}=-\Delta G_{\text {des }}$ is directly related to the corresponding current peak potential. Therefore, it is possible to compare the electrosorption behavior of TU on both $\mathrm{Ag}(111)$ and $\mathrm{Au}(111)$ considering the better defined electrodesorption peak $\mathrm{C}_{1}$. Under comparable conditions, that is, the same solution composition, applied potential routine, and temperature and a similar adsorbate array on both metals, as occurs for TU on $\mathrm{Ag}(111)$ and $\mathrm{Au}(111)$,

(52) Shumilova, N. A.; Zhutaeva, G. V. In Encyclopedia of Electrochemistry of the Elements; Bard, A. J., Ed.; Marcel Dekker: New York, 1978; Chapter VIII-1, pp 66-67.

(53) Schmid, G. M.; Curley-Fiorino, M. E. In Encyclopedia of Electrochemistry of the Elements; Bard, A. J., Ed.; Marcel Dekker: New York, 1975; Chapter IV-3, pp 118-124.

(54) Halley, J. W.; Walbran, S. In Interfacial Electrochemistry; Wieckowski, A., Ed.; Marcel Dekker: New York, 1999; p 9. the difference in the adsorption free energy change entering equilibrium 3 should be reflected in the difference between the corresponding voltammetric electrodesorption peaks, $\Delta E_{\mathrm{C} 1} \equiv E_{\mathrm{C} 1}\{\mathrm{Ag}(111)\}-E_{\mathrm{C} 1}\{\mathrm{Au}(111)\}$. Accordingly, in the reversible electroadsorption/electrodesorption cycle, the value of $\Delta E_{\mathrm{C} 1}$ can be expressed as the sum of energy terms from stages $1 \mathrm{~S}$ to $2 \mathrm{D}$,

$$
\Delta E_{\mathrm{C} 1}=\Delta E_{\mathrm{ct}}+\Delta E_{\mathrm{des}}+\Delta E_{\mathrm{A}-\mathrm{A}}+\Delta E_{\mathrm{A}-\text { solv }}+\Delta E_{\mathrm{Me}-\text { solv }}
$$

where $\Delta E_{\mathrm{ct}}, \Delta E_{\mathrm{des}}, \Delta E_{\mathrm{A}-\mathrm{A}}, \Delta E_{\mathrm{A}-\text { solv }}$, and $\Delta E_{\mathrm{Me}-\text { solv }}$ are the energy changes involved in stages $1 \mathrm{D}, 2 \mathrm{D}, 1 \mathrm{~S}$, and $2 \mathrm{~S}$, respectively. In eq 4 , the solvation energy differences of thioureate species for the same solution composition and the corresponding entropy differences from the common structural arrays of the metal substrates and adsorbate layers are also assumed as negligible. Similarly, since the final ordered TU arrays on $\mathrm{Au}(111)$ and $\mathrm{Ag}(111)$ correspond to compact, hexagonal $d_{\mathrm{n}}=0.33 \mathrm{~nm}$ structures, ${ }^{20,33}$ their contributions to $\Delta E_{\mathrm{A}-\mathrm{A}}$ also cancel for these substrates. Therefore, the only relevant terms to be considered for comparing TU adsorption energies on $\operatorname{Ag}(111)$ and $\mathrm{Au}(111)$, at constant $\mathrm{pH}$, are those involving the metal substrate.

As a first approximation $E_{\mathrm{ct}}=-n e_{0} \phi$, where $\phi$ is the work function of the metal, $n$ is the number of electrons per each reacting molecule, and $e_{0}$ is the electron charge. Assuming that the change in the energy levels by the adsorption process is similar for both metals and a one electron transfer process occurs on both substrates, ${ }^{20,33} n$ $=1$ for both $\mathrm{Au}(111)$ and $\mathrm{Ag}(111)$. For ideal terminated $\mathrm{Ag}(111)$ and $\mathrm{Au}(111)$ surfaces, $\phi_{\mathrm{Ag}}=428.78 \mathrm{~kJ} \mathrm{~mol}^{-154}$ and $\phi_{\mathrm{Au}}=509.5 \mathrm{~kJ} \mathrm{~mol}^{-1},{ }^{55}$ resulting in $\Delta E_{\mathrm{ct}}=80.7 \mathrm{~kJ}$ $\mathrm{mol}^{-1}$. For water, $\Delta E_{\mathrm{Me}-\text { solv }}=-5 \mathrm{~kJ} / \mathrm{mol}$ has been estimated. ${ }^{56}$ Differences in TU electrodesorption peak energies (Table 1) from $\operatorname{Ag}(111)\left(E_{\mathrm{C} 1}=-1.21 \mathrm{~V}\right)$ and $\mathrm{Au}(111)$ substrates $\left(E_{\mathrm{C} 1}=-0.83 \mathrm{~V}\right)^{33}$ are $\Delta E_{\mathrm{C} 1}=-0.38$ $\mathrm{V}=36.7 \mathrm{~kJ} \mathrm{~mol}^{-1}$ in a single-electron charge-transfer process. Introducing these values into eq 4 , we obtain

$$
\begin{array}{r}
\Delta E_{\mathrm{des}}=35.7 \mathrm{~kJ} / \mathrm{mol}-80.7 \mathrm{~kJ} / \mathrm{mol}-(-5 \mathrm{~kJ} / \mathrm{mol})= \\
-40.0 \mathrm{~kJ} / \mathrm{mol}
\end{array}
$$

The result from eq 5 shows, in our case, the outstanding role of the metal substrate in comparing adsorption energy values. This conclusion can be extended to experimental data obtained in alkaline media (Table 1). While peak position $E_{\mathrm{C} 1}$ shifts by almost $10 \%$ in going from neutral to alkaline solution, the adsorption energy difference remains essentially constant, independent of $\mathrm{pH}$.

The $\Delta E_{\text {des }}=-40.0 \mathrm{~kJ} / \mathrm{mol}$ estimated from electrodesorptive peak positions for TU on $\mathrm{Ag}(111)$ and $\mathrm{Au}(111)$ (Table 1) can also be extended to ETU adsorption on both metals, given the similar voltammetric peak positions obtained for TU and ETU under similar experimental conditions (Table 1). This value of $\Delta E_{\mathrm{des}}$ is also comparable to the desorption energy differences calculated for other sulfur-containing molecules on these same substrates. ${ }^{57}$ However, it should be noted that for the latter, a direct application of the above reversible electrosorption cycle is rather uncertain because no clear-cut voltammetric

(55) Pirug, G.; Bonzel, H. P. In Interfacial Electrochemistry; Wieckowski, A., Ed.; Marcel Dekker: New York, 1999; p 270.

(56) Kuznetsov, A.; Maslii, A. N.; Shapnik, M. S. Russ. J. Electrochem. 2000, 36, 1309

(57) Azzaroni, O.; Vela, M. E.; Andreasen, G.; Carro, P.; Salvarezza R. C. J. Phys. Chem. B 2002, 106, 12267. 
electroadsorption process can be observed and the electrodesorption mechanism is complicated by a denucleation process. $^{35}$

Therefore, the comparative evaluation of $\mathrm{Ag}(111)$ - and $\mathrm{Au}(111)$-adsorbate interactions is consistent with the global conclusions of the structural studies that suggest that in the formation of S, TU, and ETU SAMs on these metals, the substrate-adsorbate interaction dominates the final structures since in all cases a direct correlation with S-head adsorption at high-symmetry $\operatorname{Ag}(111)$ and $\mathrm{Au}(111)$ sites can be established.

\section{Conclusions}

We have compared S, TU, and ETU adsorption on $\operatorname{Ag}(111)$ from their aqueous solutions, by combining data from an STM operating under potential control along with voltammetry using different potential-time routines. A single electroadsorption-desorption pair of current peaks at ca. $-1.2 \mathrm{~V}$ (SCE) is associated with the initial stages of adlayer formation or the sulfur-containing molecules. Molecular resolution STM images of the early adsorption stages on $\operatorname{Ag}(111)$ reveal the formation of a common $\operatorname{Ag}(111)-(\sqrt{ } 7 \times \sqrt{ } 7) \mathrm{R} 19.1^{\circ}$ hexagonal structure with $d_{\mathrm{n}}=$ $0.44 \mathrm{~nm}$ intermolecular spacing. This is the only ordered structure observed for ETU, due to steric constraints. Adsorbed TU compresses into ordered $d_{\mathrm{n}}=0.38 \mathrm{~nm}$ and $d_{\mathrm{n}}=0.33 \mathrm{~nm}$ hexagonal arrays by increasing either the applied potential at a given time or the holding time at a preset potential. The most compact structure of adsorbed
TU is a result of hydrogen bonding. In the case of sulfur, increasing either time or potential results in sulfur-trimer formation. All ordered structures can be related with S-containing molecule adsorption on high-symmetry $\mathrm{Ag}(111)$ sites and a common voltammetric electrodesorption current peak at a single position reflecting the influence of the substrate-adsorbate bond.

From the TU peak position in neutral and alkaline media, a pH-independent difference in adsorption energies $\Delta E_{\text {ads }} \approx 40 \mathrm{~kJ} / \mathrm{mol}$ between $\mathrm{Ag}(111)$ and $\mathrm{Au}(111)$ substrates has been determined. A similar conclusion can be drawn from the voltammetric data of ETU. The similarity of the voltammetric response and the different final adsorbate structure of all three species confirm the complexity involved in TU electroadsorption reactions on metal singlecrystal surfaces and the care with which the effect of substituents has to be considered when analyzing this type of complex surface reaction.

Acknowledgment. This Research was funded by Agencia Nacional de Promoción Científica y Tecnológica (Argentina) PICT 99-5030 and CONICET (Argentina) PIP 0897-98, PIP 4376-96, and PICT 98-06-03351. V.B. expresses thanks for the fellowship granted by CONICET. The authors also thank G. Andreasen (INIFTA) and A. Trigubó (CITEFA) for their assistance in sample preparation and J. Massarutti (INIFTA) for his assistance in process control.

LA034005W 